\title{
ON TIME-OPTIMAL PROCEDURE FOR ANALOG SYSTEM DESIGN
}

\author{
A. Zemliak, E. Rios, P. Miranda, K. Zemliak \\ Facultad de Ciencias Físico Matemáticas, Universidad Autónoma de Puebla \\ Av. San Claudio y 18 sur s/n, Ciudad Universitaria, C.P. 72570, Puebla, Pue. \\ México, Tel. 222-2295-500 Ext. 2123 \\ E-Mail: azemliak@fcfm.buap.mx
}

Received: October 23's 2001. Accepted: February $4^{d}, 2003$

\begin{abstract}
The process of any analog system design has been formulated on the basis of the control theory application. This approach produces many different design strategies inside the same optimization procedure and allows determining the problem of the optimal design strategy existence from the computer time point of view. Different kinds of system design strategies have been evaluated from the operations number. The general methodology for the analog system design was formulated by means of the optimum control theory. The main equations for this design methodology were elaborated. These equations include the special control functions that are introduced artificially. This approach generalizes the design process and generates an infinite number of the different design strategies. The problem of the optimum design algorithm construction is defined as the minimum-time problem of the control theory. Numerical results of some electronic circuit design demonstrate the efficiency and perspective of the proposed methodology. These examples show that the computer time gain of the optimal design strategy with respect to the traditional design strategy increases when the size and complexity of the system increase. An additional acceleration effect of the design process has been discovered by the analysis of various design strategies with the different initial points. This effect is displayed for all analyzed circuits and it reduces additionally the total computer time for the system design.
\end{abstract}

\section{RESUMEN}

El proceso de diseño de un sistema análogo ha sido formulado en la base de aplicación de la teoría de control. Esta concepción produce varias estrategias del diseño dentro del mismo procedimiento de optimización y permite determinar el problema de existencia de una estrategia óptima de diseño de punto de vista en el tiempo de cómputo. Diferentes estrategias de diseño fueron evaluadas desde el punto de vista del número de operaciones. La metodología general del diseño de sistemas análogos fue desarrollada en la base de la teoría de control óptimo. Las ecuaciones principales de esta metodología fueron elaboradas. Estas ecuaciones incluyen las funciones de control especiales. Este enfoque generaliza el proceso de diseño y produce un número infinito de diferentes estrategias de diseño. El problema de la construcción de un algoritmo óptimo esta definido como un problema de tiempo mínimo de la teoría de control óptimo. Los resultados numéricos del diseño de varios circuitos electrónicos muestran la eficiencia y la perspectiva de una nueva metodología. Estos ejemplos exponen que la ganancia del tiempo de cómputo para la estrategia óptima con respecto a la estrategia tradicional crece cuando el tamaño y la complejidad del sistema se aumentan. Un efecto de aceleración adicional del proceso de diseño ha sido descubierto en la base del análisis de diferentes estrategias con varios puntos iniciales. Este efecto aparece en todos los ejemplos analizados y puede reducir adicionalmente el tiempo total de diseño de sistemas.

KEYWORDS: Time-optimal system design, Control theory approach, Acceleration effect. 


\section{INTRODUCTION}

One of the main problems of a large system design is the excessive computer time that is necessary to achieve the optimal point of the design process. This problem has a huge significance because it has a lot of applications, for example on VLSI electronic circuit design.

Any system design strategy includes two main parts as a rule: the model of the system, which can be simulated as algebraic equations or differential-integral equations and the optimization procedure that achieves the objective function optimum point.

The traditional design strategy for the system design has two fixed determined parts. The first part is the mathematical model of the physical system and the second one is the optimization procedure. In terms of this conception it is possible to change the optimization strategy and use different models and different analysis methods. However, the time of the large-scale circuit analysis and the time of optimization procedure increase when the network scale increases.

There are some powerful methods that reduce the necessary time for the circuit analysis. Because a matrix of the largescale circuit is a very sparse, the special sparse one matrix techniques are used successfully for this purpose [1-4]. Another approach to reduce the amount of computational time required for the linear and nonlinear equations is based on the decomposition techniques. The partitioning of a circuit matrix into bordered-block diagonal form can be done by branches tearing as in [5], or by nodes tearing as in [6] and jointly with direct solution algorithms gives the solution of the problem. The extension of the direct solution methods can be obtained by hierarchical decomposition and macromodel representation [7]. Another approach for achieving decomposition at the nonlinear level consists of a special iteration techniques and has been realized in [8] for the iterated timing analysis and circuit simulation. The optimization technique that is used for the circuit optimization and design, exerts a very strong influence on the total necessary computer time too. The numerical methods are developed both for the unconstrained and for the constrained optimization [9-10]. The practical aspects of use of these methods are developed for VLSI circuit design, yield, timing and area optimization [11-13]. It is possible to suppose that the circuit analysis methods and the optimization procedures will be improved later on.

On the contrary, it is possible to reformulate the total design problem and generalize it to obtain a set of different design strategies inside the same optimization procedure. It is clear that a finite but a large number of different strategies includes more possibilities for the selection of one or several design strategies that are time-optimal or quasi-time-optimal ones. This is especially right if we have an infinite number of the different design strategies. Contrary to the traditional design strategy, the modified traditional design strategy has only one part, because all system parameters are determined as independent and the objective function of the optimization procedure includes additional penalty functions that describe the model of the physical system. In this case the equations of the model of the physical system disappear. On the other hand, it is possible to re-determine the total design problem, to generalize it, to obtain a set of the different design strategies. First of all, we define the time-optimal design strategy as the algorithm that achieves the optimum point of the objective function of the design process at the minimal computer time. The main problem of this formulation is the searching of the special conditions, which need to be satisfied for the optimal algorithm construction.

The idea to use the control theory, which was introduced in [14], is developed now for the design of the systems that are described by the nonlinear algebraic equation model. This methodology generalizes the design problem and can reduce the total necessary computer design time. First of all the evaluation of the operations number for different design strategies has been done. The main system of equations that describes the general design process is determined. The time-optimal system design procedure is defined as a minimal-time problem of the control theory and gives the possibility to use the specific methods of this theory. Different examples of the electronic circuit design have been analyzed using the proposed methodology. In contrast to [14-16] the present paper defines the new design problem formulation in continuous form. 


\section{PRELIMINARY CONSIDERATIONS AND PROBLEM FORMULATION}

The design process for any physical system design can be defined as the problem of objective function $C(X)$ minimization, $X \in R^{N}$ with the system of constraints. It is supposed that the minimum of the objective function $C(X)$ achieves all design objects and the constraint system is the mathematical model of the physical system. It is supposed also that the physical system model can be described as the system of nonlinear equations:

$$
\begin{array}{r}
g_{j}(X)=0 \\
j=1,2, \ldots, M
\end{array}
$$

The vector $X$ can be separated in two parts: $X=\left(X^{\prime}, X^{\prime \prime}\right)$. The vector $X^{\prime} \in R^{K}$ can be named as the vector of independent variables where $K$ is the number of independent variables and the vector $X^{\prime \prime} \in E^{M}$ is the vector of dependent variables, where $N=K+M$. It is clear that this separation is very conditional, because any variable can be defined as independent or dependent parameter. If the electronic system is described, it is more traditional and natural to define the system elements as independent variables and the physical parameters (voltages, currents, and so on) as dependent variables, but it is not obligatory.

The optimization process for the objective function $C(X)$ minimization for two-step procedure can be defined as following vector equation in general case:

$$
X^{s+1}=X^{s}+t_{s} \cdot H^{s}
$$

with constraints (1), where $s$ is the iterations number, $t_{s}$ is the iteration parameter, $t_{s} \in R^{1}, H$ is the direction of the objective function $C(X)$ decreasing. The vector $H$ is the function of $C(X)$. This is a typical formulation for the constrained optimization problem. This problem can be transformed to the unconstrained optimization problem for $K=N-M$ variables. It is very easy to do this transformation if we solve the system (1) for $M$ components of the vector $X$ and substitute these components into the function $C(X)$. In this case the design problem is defined in more traditional form as an unconstrained optimization process in the space of independent variables:

$$
X^{\prime s+1}=X^{\prime s}+t_{s} \cdot H^{s}
$$

with the system (1) which is solved in each step of the optimization procedure.

The specific character of the design process at least for the electronic systems consists in the fact that it is not necessary to fulfill the conditions (1) for all steps of the optimization process. It is quite enough to fulfill these conditions for the final point of the design process.

The problem by (1) and (3) can be redefined in the form when there is no difference between independent and dependent variables. All components of the vector $X$ can be defined as independent. This is the main idea for the penalty function method application. In this case the vector function $H$ is the function of objective function $C(X)$ and the additional penalty function $\varphi(X): H^{s}=f\left(C\left(X^{s}\right), \varphi\left(X^{s}\right)\right)$. The penalty function structure includes all equations of the system (1) and can be defined for example as:

$$
\varphi\left(X^{s}\right)=\frac{1}{\varepsilon} \sum_{i=1}^{M} g_{i}^{2}\left(X^{s}\right)
$$

In this case we define the design problem as the unconstrained optimization (2) in the space $R^{N}$ without any additional system but for the other type of the objective function $F(X)$. This function can be defined for example 
as an additive function: $F(X)=C(X)+\varphi(X)$. In this case we have the minimum of the initial objective function $C(X)$ and comply with the system (1) in the final point of the optimization process (in the minimal point of the function $F(X)$ ). This method can be named as modified traditional design method. This method produces another design strategy and another trajectory line in the space $R^{N}$.

On the other hand it is possible to generalize the idea of additional penalty function application if to make up the penalty function as one part of the system (1) only and the other part of this system is defined as constraints [15]. In this case the penalty function includes first $Z$ items only, $\varphi\left(X^{s}\right)=\frac{1}{\varepsilon} \sum_{i=1}^{Z} g_{i}^{2}\left(X^{s}\right)$ where $Z \in[0, M]$ and $M-Z$ equations make up one modification of the system (1):

$$
\begin{gathered}
g_{j}(X)=0 \\
j=Z+1, Z+2, \ldots, M
\end{gathered}
$$

It is clear that each new value of the parameter $Z$ produces a new design strategy and a new trajectory line. This idea can be generalized more in case when the penalty function $\varphi(X)$ includes $Z$ arbitrary equations from the system (1). The total number of different design strategies is equal to $2^{M}$ if parameter $Z$ runs all values of the region $[0, M]$. All these strategies exist inside the same optimization procedure. The optimization procedure is realized in the space $R^{K+Z}$. The number of the dependent variables $M$ increases rapidly with the system complexity increasing. The number of different design strategies increases exponentially in this case. It is clear that these different strategies have various computer times because they have the different operation number. It is appropriate in this case to define the problem of the search of an optimal design strategy that has the minimal computer time. Here and further the optimality is defined as the computer time minimization.

To obtain a concrete evaluation and to analyze some examples we need to define an optimization procedure. It is possible to use some different methods of the unconstrained optimization for the function $F(X)$ : the zero order methods (method of conjugate directions, Hooke-jeeves method, Simplex method and so on), the first order methods (the different variants of the gradient method), the second order methods (the different variants of the Newton's method), the quasi-Newton methods (the method of conjugate gradients, Davidon-Fletcher-Powell (DFP) method [17] and so on).

To simplify a concrete exposition of the main idea for the formulation of the design process as the control theory problem it is convenient to select the gradient method for the optimization procedure. This method has some defects but serves as the basis for many other algorithms. Another supposition consists of the idea of changing the numerical equation (2) by the differential equation:

$$
\frac{d X}{d t}=f(X, U)
$$

It means that the main problem of the design process can be formulated as the problem of the integration of this system with additional conditions (5). The structure of the function $H$ for the gradient method can be defined as:

$$
H \equiv f(F(X, U))=-\frac{\partial F(X, U)}{\partial X}
$$

This function defines the direction of the movement during the optimization process. 


\section{EVALUATION OF OPERATIONS NUMBER}

The traditional design strategy. The traditional design strategy includes two systems of the equations. It is supposed that the optimization procedure for the system design process can be defined as the system of the ordinary differential equations for the independent variables, for example as:

$$
\begin{aligned}
& \frac{d x_{i}}{d t}=-b \cdot \frac{\delta}{\delta x_{i}} C(X) \\
& i=1,2, \ldots, K
\end{aligned}
$$

where $C(X)$ is the objective function of the design problem; $b$ is the iteration parameter; the operator $\frac{\delta}{\delta x_{i}}$ hear and below means $\frac{\delta}{\delta x_{i}} \varphi(X)=\frac{\partial \varphi(X)}{\partial x_{i}}+\sum_{p=K+1}^{K+M} \frac{\partial \varphi(X)}{\partial x_{p}} \frac{\partial x_{p}}{\partial x_{i}}$. The gradient method is utilized as the main optimization procedure here and below. However it is not important what kind of the optimization method is used. It is only necessary to prepare the optimization procedure as the system of ordinary differential equations for the independent variables.

The model of the system we can determine as the system of constraints from the optimization theory point of view. It is supposed that this model is described as the system of the nonlinear algebraic equations:

$$
\begin{array}{r}
g_{j}(X)=0 \\
j=1,2, \ldots, M
\end{array}
$$

The operations number for the solution of the system (8) by the Newton's method is equal to $S \cdot\left[M^{3}+M^{2}(1+P)+M P\right]$, where $P$ is the average operations number for the function $g_{j}(X)$ calculation; $S$ is the iteration number of Newton's method for the system (8) solution. The operations number for one step $\Delta t$ of the system (7) integration for the Newton's method is equal to $K+C \cdot(1+K)+(1+K) \cdot S \cdot\left[M^{3}+M^{2}(1+P)+M P\right]$ where $C$ is the operations number for the objective function calculation. The total operations number for the solution of the problem (7)-(8), when the Newton's method is used is equal to:

$$
N_{1}=L_{1}\left\{K+(1+K)\left\{C+S \cdot\left[M^{3}+M^{2}(1+P)+M P\right]\right\}\right\}
$$

where $L_{1}$ is the total steps number of the optimization algorithm. The Newton's method for the system's model solution was taken into consideration below to evaluate the total operations number. The results for the quasi-Newton method are very similar.

The modified traditional design strategy. The modified traditional strategy is determined as the system of optimization procedure equations without any constraints [15]. In this case the number of independent variables is equal to $K+M$. The principal system is given by:

$$
\begin{aligned}
& \frac{d x_{i}}{d t}=-b \cdot \frac{\delta}{\delta x_{i}} F(X) \\
& i=1,2, \ldots, K+M
\end{aligned}
$$

where $F(X)$ is the general objective function, $F(X)=C(X)+\frac{1}{\varepsilon} \sum_{j=1}^{M} g_{j}^{2}(X)$. 
The total operations number for the problem (10) solution is equal to:

$$
N_{2}=L_{2}\{K+M+(1+K+M) \cdot[C+(P+1) M]\}
$$

The general design strategy. This idea was formulated at the heuristic level in [18] without any proof or comparison of the different strategies. This approach was developed more adequately in [15]. It is possible to define the general design strategy as the strategy which has the variable number of independent parameters that is equal to $K+Z$. In this case the following two systems are used:

$$
\begin{gathered}
\frac{d x_{i}}{d t}=-b \cdot \frac{\delta}{\delta x_{i}} F(X) \\
i=1,2, \ldots, K+Z \\
g_{j}(X)=0 \\
j=Z+1, Z+2, \ldots, M
\end{gathered}
$$

where $F(X)=C(X)+\frac{1}{\varepsilon} \sum_{j=1}^{Z} g_{j}^{2}(X)$. In this case the total operations number $N_{3}$ for the solution of the systems (12), (13) is equal to:

$$
N_{3}=L_{3}\left\{K+Z+(1+K+Z)\left\{C+(P+1) Z+S \cdot\left[(M-Z)^{3}+(M-Z)^{2}(1+P)+(M-Z) P\right]\right\}\right\}
$$

This formula is turned to the formula (9) when $Z=0$ and is turned to the formula (11) when $Z=M$. Analysis of the operations number $N_{3}$ as the function of $Z$ by formula (14) gives us the conditions for the minimum computer time calculation. This general strategy almost has no preference in computer time as shown in [15] when the system (13) is linear or quasi-linear. In this case the iteration number for the Newton's method $S$ is equal to 1 and the traditional approach is optimal.

It is supposed also that the iteration number $L_{3}$ and the operation number $C$ for the objective function calculation have dependencies from the independent variables number by the following law:

$$
L_{3}=L_{0} \cdot(K+Z)^{n} ; \quad C=C_{0} \cdot(K+Z)^{m}
$$

These are ordinary assumptions and the principal problem is the value of the power $n$ and $m$. On the other hand the iterations number for the Newton's method $S$ has no dependency from the order of the system (13) in the first approximation and is equal to constant value $S_{0}$. This value is equal to 4 or 5 in practice to achieve the precision $\delta=10^{-10}-10^{-12}$. The average operations number $P$ for the function $g_{j}(X)$ calculation has no dependency from $Z$ if it is supposed that an electronic system is analyzed. This is correct because the admittance matrix of the electronic system is very sparse. It is supposed that this value is constant and equal to $P_{0}$. In this case the formula (14) for the function $N_{3}(Z)$ calculation is transformed to the next form:

$$
\left.N_{3}(Z)=L_{0} \cdot(K+Z)^{n} \cdot\left\{K+Z+(1+K+Z) \cdot C_{0} \cdot(K+Z)^{m}+Z\left(1+P_{0}\right)+S_{0} \cdot\left((M-Z)^{3}+(M-Z)^{2}\left(1+P_{0}\right)+(M-Z) P_{0}\right)\right]\right\}
$$

In accordance with the principal definition of the optimum design strategy we can find this optimum strategy by the analysis of this formula. We need to find the optimum point $Z_{\text {opt }}$ where the function $N_{3}(Z)$ has the minimum value. 
If the optimum point $Z_{\text {opt }}$ is equal to $O$ it means that the traditional strategy is the optimum one. If the optimum point $Z_{\text {opt }}$ is equal to $M$ it means that the modified traditional strategy is the optimum one. If the optimum point $Z_{\text {opt }}$ belongs to the region $(0, M)$, it means that one of the intermediate strategies is the optimum one. The derivative of the function $N_{3}(Z)$ is given by formula:

$$
\begin{aligned}
& N_{3}^{\prime}(Z)=L_{0} n(K+Z)^{n-1}\left\{K+Z+(1+K+Z)\left[C_{0}(K+M)^{m}+Z\left(1+P_{0}\right)+S_{0}\left((M-Z)^{3}+(M-Z)^{2}\left(1+P_{0}\right)+(M-Z) P_{0}\right)\right]\right\} \\
& +L_{0}(K+Z)^{n}\left\{1+C_{0}\left(K+M^{m}+(1+K+Z Z)\left(1+P_{0}\right)+S_{0}\left[(M-Z)^{3}+(M-Z)^{2}\left(1+P_{0}\right)+(M-Z) P_{0}-(1+K+Z)(3 M-Z)^{2}+2(M-Z)\left(1+P_{0}\right)+P_{0}\right)\right]\right\}
\end{aligned}
$$

It is interesting to analyze the conditions that can give at least one minimum point within the region [0, M]. To obtain this minimum point as an inside point of this region it is necessary to provide two conditions for the derivative in the boundaries: $N_{3}^{\prime}(0)<0$ and $N_{3}^{\prime}(M)>0$.

Lets define an additional parameter $q=\frac{M}{K}$. The derivative $N_{3}^{\prime}(0)$ in assumption that $m=1, \quad Z=0$ and $M, K \rightarrow \infty$ is given by formula:

$$
N_{3}^{\prime}(0)=L_{0} K^{n+1} M^{2} S_{0}[(1+n) q-3]
$$

It is necessary to provide a special condition for the parameter $n$ to fulfill the condition $N_{3}^{\prime}(0)<0$. This condition is given by formula $n<\frac{3}{q}-1$. The parameter $q$ for the majority of the systems is lesser than or equal to 1 . In that case we have the next condition for the parameter $n: n<2+\varepsilon$. On the other hand the derivative $N_{3}^{\prime}(Z)$ in the point $M$ when $M, K \rightarrow \infty$ is given by the following form:

$$
N_{3}^{\prime}(M)=L_{0}(K+M)^{n+1}\left[C_{0}(1+n)+\frac{(1+K+2 M+n M)\left(1+P_{0}\right)}{K+M}-S_{0} P_{0}\right]
$$

It is supposed that the order $n$ is equal to 2 . In that case the main inequality to provide the condition $N_{3}^{\prime}(M)>0$ is given by $3 C_{0}+\frac{1+4 q}{1+q}\left(1+P_{0}\right)-S_{0} P_{0}>0$. This formula is transformed when $q \rightarrow 1$ and $C_{0} \approx P_{0}$ to the following condition: $P_{0}\left(5.5-S_{0}\right)+2.5>0$. In the case when $n=1$ another condition is given by $P_{0}\left(4-S_{0}\right)+2>0$. There is a possibility to obtain the condition $N_{3}^{\prime}(M)>0$ if the iteration number $S_{0}$ is equal to 4 or 5 . Therefore the optimum point $Z_{\text {opt }}$ is within the region $[K, K+M]$ in this case. This analysis serves as the base for the subsequent more detailed investigation of the general design strategy idea.

\section{THE TIME-OPTIMAL SYSTEM DESIGN PROBLEM FORMULATION}

It is possible to determine the problem of any system design as the problem of optimal control. The principal system of equations can be determined as:

$$
\begin{gathered}
\frac{d x_{i}}{d t}=f_{i}(X, U) \\
i=0,1, \ldots, N
\end{gathered}
$$

and

$$
\left(1-u_{j}\right) g_{j}(X)=0
$$




$$
j=1,2, \ldots, M
$$

where $N=K+M ; \quad x_{0}$ is the additional variable; $U$ is the vector of control variables, $U=\left(u_{1}, u_{2}, \ldots, u_{M}\right)$; $u_{j} \in \Omega ; \Omega=\{0 ; 1\}$. The functions of the right part of the system (19) include the penalty function and are determined as:

$$
f_{i}(X, U)=-b \frac{\delta}{\delta x_{i}}\left\{C(X)+\frac{1}{\varepsilon} \sum_{j=1}^{M} u_{j} g_{j}^{2}(X)\right\}
$$

$i=1,2, \ldots, K$

$$
f_{i}(X, U)=-b \cdot u_{i-K} \frac{\delta}{\delta x_{i}}\left\{C(X)+\frac{1}{\varepsilon} \sum_{j=1}^{M} u_{j} g_{j}^{2}(X)\right\}+\frac{\left(1-u_{i-K}\right)}{d t}\left\{-X_{i}^{\prime}+\eta_{i}(X)\right\}
$$

$i=K+1, K+2, \ldots, N$

where $x_{i}^{\prime}$ is equal to $x_{i}(t-d t) ; \eta_{i}(X)$ is the implicit function $\left(x_{i}=\eta_{i}(X)\right)$ that is determined by the system (20). The control variables $u_{j}$ are introduced artificially to generalize the design strategy. These variables have the time dependency in general case. The sense of the control function $u_{j}$ is next: the equation number $j$ is presented in the system (20) and the term $g_{j}^{2}(X)$ is removed from the right part of the systems (21), (21') when $u_{j}=0$, and on the contrary, the equation number $j$ is removed from the system (20) and is presented in the right part of the systems (21), (21') when $u_{j}=1$. The index $j$ is equal to $i-K$. The equation number $j$ is removed from (20) and the dependent variable $x_{K+j}$ is transformed to the independent when $u_{j}=1$. This independent parameter is defined by the formulas (19), (21'). In this case there is no difference between formulas (21) and (21'), because the parameter $x_{K+j}$ is an ordinary independent parameter. On the other hand, the equation (19) with the right part (21') is transformed to the identity $\frac{d x_{i}}{d t}=\frac{d x_{i}}{d t}$, when $u_{j}=0$ because $\eta_{i}(X)-x_{i}^{\prime}=x_{i}(t)-x_{i}(t-d t)=d x_{i}$. It means that at this time moment the parameter $x_{i}$ is dependent one and the current value of this parameter can be obtained from the system (20) directly. This transformation of the vectors $X^{\prime}$ and $X^{\prime \prime}$ can be done at any time moment. The function $f_{0}(X, U)$ is determined as the necessary calculation time for one step of the system (19) integration. In this case the additional variable $\boldsymbol{X}_{0}$ is determined as the total computer time $T$ for the system design.

In this case we determine the problem of the optimal system design as the classical minimum-time problem of the optimum control. In that context the aim of optimal control is to result each function $f_{i}(X, U)$ to zero for the final time $t_{\text {fin }}, f_{i}\left(X\left(t_{\text {fin }}\right), U\left(t_{\text {fin }}\right)\right)=0$ and to minimize the total computer time $X_{0}$. By this formulation the general design strategy of the previous section is the particular case only. It is possible to re-determine this general design strategy as method with the fixed values of all control functions $u_{j}$. The total number of the different design strategies which is produced by the general design strategy is equal to $2^{M}$. On the contrary, the idea that defines the design process by means of equations (19)-(21) generates an infinite number of the different design strategies. Each design strategy has its own trajectory. It is clear that the comparison of the different types of trajectories is adequate only in the case when the final trajectory point is the same. On the other hand the objective function $C(X)$ has a set of local minimal points, because the design problem is a nonlinear problem in general. It is necessary to put the additional simple conditions to achieve the same point of the objective function for the different design strategies. However the non-simple problem is not a specific feature of the new design problem formulation. We always have 
this type of problem when we begin the design process from the different start points. It is supposed below that the simple conditions are provided.

To minimize the total design computer time it is necessary to find the optimal behavior of the control functions $u_{j}$ during the design process. There is one difficulty at the consideration of the system (19). The functions $f_{i}(X, U)$ are not continued as the temporal functions in a finite number of the time points because the control functions $u_{j}$ take the values 0 or 1 . The minimum-time problem for the system (19) with non-continued or non-smoothed functions (21) can be solved most adequately by means of Pontryagin's maximum principle [19]. For the classical Pontryagin's form of the optimal control problem formulation it is necessary to define the conjugate system for the additional functions $\psi_{i}:$

Hamiltonian is determined as:

$$
\frac{d \psi_{i}}{d t}=-\sum_{\substack{l=0 \\ i=0,1, \ldots, N}}^{N} \frac{\partial f_{l}(X, U)}{\partial x_{i}} \cdot \psi_{l}
$$

$$
H(X, U, \Psi)=\sum_{i=0}^{N} \psi_{i} f_{i}(X, U)
$$

This function has supreme value during the optimal trajectory with the Pontryagin's maximum principle:

$$
\begin{gathered}
M(X, \Psi)=\sup H(X, U, \Psi) \\
u \in \Omega
\end{gathered}
$$

The main problem of the maximum principle application in that formulation is the unknown vector $\Psi_{0}$ of initial values of the functions $\psi_{i}$. This problem has adequate solution only for linear functions $f_{i}(X, U)$, for example in [20]. For the nonlinear case it is possible to use some approximate iterative algorithms [21-24] for the solution of the problem (19)-(24). Some of these algorithms are based on the boundary problem solution for $2 \times(N+1)$ order equations system (19), (22). The iteration process for the numerical integration of this system includes consecutive iterations of Cauchy problem solution.

\section{PASSIVE AND ACTIVE NONLINEAR CIRCUITS DESIGN}

Some nonlinear electronic circuits have been investigated to demonstrate the new system design approach based on the optimal control theory. These examples have various nodal numbers from 3 to 5 for the passive nonlinear circuits and from 3 to 7 for the active nonlinear circuits. It means that the number of dependent arguments $M$ of the design process has been changed from 3 to 7 . The design process has been realized on DC mode for all circuits. The objective function $C(X)$ has been determined as the sum of the squared differences between beforehand defined values and current values of the nodal voltages for some nodes with additional inequalities for some circuit elements. The final value of the objective function of the design process was defined as $10^{-8}-10^{-10}$ for the different examples. The analysis of all circuits was provided for two different optimization methods, the gradient method and the DFP method. The iteration parameter $t_{s}$ was selected and optimized separately for each strategy to obtain the minimum iteration steps.

5.1 Passive Nonlinear Circuits

Detailed analysis of some different circuits for $M=3,4,5$ are presented below. 


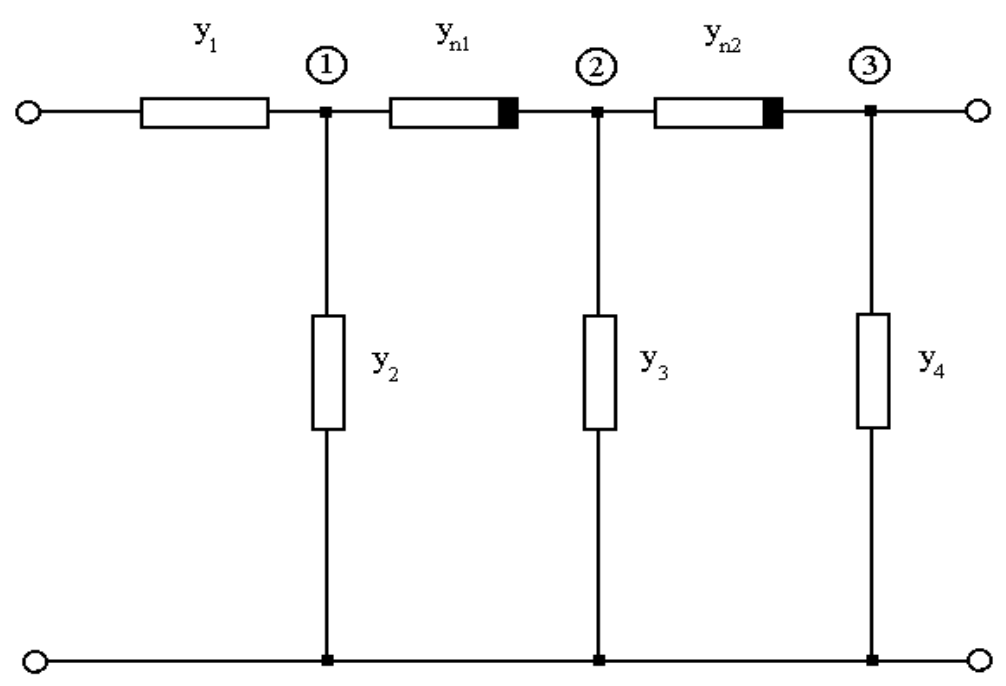

Figure 1. Circuit topology for $K=4, M=3$.

Example 1. In Fig. 1 there is a circuit that has 4 independent variables $(K=4)$ as admittance $y_{1}, y_{2}, y_{3}, y_{4}$ and 3 dependent variables $(M=3)$ as nodal voltages $V_{1}, V_{2}, V_{3}$ at the nodes $1,2,3$. The nonlinear elements are defined as $y_{n 1}=a_{n 1}+b_{n 1} V_{1}^{2}, \quad y_{n 2}=a_{n 2}+b_{n 2} V_{2}^{2}$. The nonlinearity parameters $b_{n 1}, b_{n 2}$ are equal to 1.0. We define the components of the vector $x$ by the formulas $x_{1}^{2}=y_{1}, x_{2}^{2}=y_{2}, x_{3}^{2}=y_{3}, x_{4}^{2}=y_{4}, x_{5}=V_{1}, x_{6}=V_{2}, x_{7}=V_{3}$. In this case we have the system of 7 differential equations as the optimization algorithm:

$$
\begin{gathered}
\frac{d x_{i}}{d t}=-b \frac{\delta}{\delta x_{i}} F(X, U), \quad i=1,2,3,4 \\
\frac{d x_{i}}{d t}=-b \cdot u_{i-4} \cdot \frac{\delta}{\delta x_{i}} F(X, U)+\frac{\left(1-u_{i-4}\right)}{d t}\left\{-x_{i}(t-d t)+\eta_{i}(X)\right\}, \quad i=5,6,7
\end{gathered}
$$

where $F(X, U)=C(X)+\frac{1}{\varepsilon} \sum_{j=1}^{3} u_{j} g_{j}^{2}\left(x_{1}, x_{2}, x_{3}, x_{4}, x_{5}, x_{6}, x_{7}\right)$. The model of the electronic system has three nonlinear algebraic equations in accordance with the electronic theory:

$$
\begin{aligned}
& g_{1}(X) \equiv\left(x_{1}^{2}+x_{2}^{2}+a_{n 1}+b_{n 1} x_{6}^{2}\right) x_{5}-\left(a_{n 1}+b_{n 1} x_{6}^{2}\right) x_{6}-x_{1}^{2}=0 \\
& g_{2}(X) \equiv-\left(a_{n 1}+b_{n 1} x_{6}^{2}\right) x_{5}+\left(x_{3}^{2}+a_{n 1}+b_{n 1} x_{6}^{2}+a_{n 2}+b_{n 2} x_{7}^{2}\right) x_{6}-\left(a_{n 2}+b_{n 2} x_{7}^{2}\right) x_{7}=0 \\
& g_{3}(X) \equiv-\left(a_{n 2}+b_{n 2} x_{7}^{2}\right) x_{6}+\left(x_{4}^{2}+a_{n 2}+b_{n 2} x_{7}^{2}\right) x_{7}=0
\end{aligned}
$$

This system is transformed in accordance with our approach to the following system:

$$
\left(1-u_{j}\right) g_{j}(X)=0, \quad j=1,2,3
$$


Table I. Complete set of design strategies for Example 1 ( $M=3)$.

\begin{tabular}{|c|c|c|c|c|c|}
\hline \multirow[t]{2}{*}{$\mathrm{N}$} & \multirow{2}{*}{$\begin{array}{l}\text { Control functions } \\
\text { vector } \\
\text { U (u1, u2, u3 ) }\end{array}$} & \multicolumn{2}{|l|}{ Gradient } & \multicolumn{2}{|c|}{ DFP method } \\
\hline & & \begin{tabular}{|l} 
Iterations \\
number
\end{tabular} & $\begin{array}{l}\text { Total design } \\
\text { time }(\mathrm{sec})\end{array}$ & \begin{tabular}{|l|l|}
$\begin{array}{l}\text { Iterations } \\
\text { number }\end{array}$ \\
\end{tabular} & $\begin{array}{l}\text { Total design } \\
\text { time }(\mathrm{sec})\end{array}$ \\
\hline 1 & 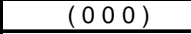 & 813 & 0.176 & 215 & 0.086 \\
\hline 2 & $\left(\begin{array}{llll}0 & 0 & 1\end{array}\right)$ & 23323 & 1.819 & 764 & 0.121 \\
\hline 3 & $\left(\begin{array}{llllllllllll}0 & 1 & 0\end{array}\right)$ & 10130 & 0.857 & 559 & 0.092 \\
\hline 4 & $\left(\begin{array}{llllll}0 & 1 & 1\end{array}\right)$ & 24602 & 0.945 & 648 & 0.061 \\
\hline 5 & $\left(\begin{array}{llll}1 & 0 & 0\end{array}\right)$ & 6732 & 0.629 & 559 & 0.092 \\
\hline 6 & $\left(\begin{array}{lllllll}1 & 0 & 1\end{array}\right)$ & 16639 & 0.951 & 630 & 0.083 \\
\hline 7 & $\left(\begin{array}{llll}1 & 1 & 0\end{array}\right)$ & 6474 & 0.377 & 557 & 0.071 \\
\hline 8 & $\left(\begin{array}{llllll}1 & 1 & 1\end{array}\right)$ & 35064 & 0.887 & 772 & 0.066 \\
\hline
\end{tabular}

The results of the analysis of the complete set of the design strategies with the fixed value of the control functions are given in Table I. The first line of the table corresponds to the traditional design strategy, the last line corresponds to the modified traditional strategy and other lines are the intermediate strategies. The total computer design time has the minimal value for the traditional design strategy in case when the gradient method is applied $(0.176 \mathrm{sec})$ and for the strategy number 4 in the case of the DFP method $(0.061 \mathrm{sec})$. These are the optimal strategies among all strategies, which were obtained with the fixed values of the control functions. However, these strategies are not optimal in general. It is necessary to find the optimal strategies by means of the additional optimization procedure.

The data of the optimal strategies are given in Table II. The control function vector of the optimal strategy has two switching points for the gradient method and one switching point for the DFP method. The computer time gain of the optimal design strategy with respect to the traditional strategy is equal to 1.6 for the gradient method and 3.7 for the DFP method.

Table II. Data of the optimal design strategies for Example $1(M=3)$.

\begin{tabular}{|r|l|l|l|l|l|l|}
\hline N & Method & $\begin{array}{l}\text { Optimal control } \\
\text { functions vector } \\
\mathrm{U}(\mathrm{u} 1, \mathrm{u} 2, \mathrm{u3})\end{array}$ & $\begin{array}{l}\text { Iterations } \\
\text { number }\end{array}$ & $\begin{array}{l}\text { Switching } \\
\text { points }\end{array}$ & $\begin{array}{l}\text { Total } \\
\text { design } \\
\text { time (sec) }\end{array}$ & $\begin{array}{l}\text { Computer } \\
\text { time gain }\end{array}$ \\
\hline 1 & Gradient Method & $(101) ;(111) ;(110)$ & 1999 & $10 ; 200$ & 0.111 & 1.6 \\
\hline 2 & DFP method & $(110) ;(111)$ & 292 & 56 & 0.023 & 3.7 \\
\hline
\end{tabular}

Example 2. In Fig. 2 there is a circuit that has 5 independent variables as admittance $y_{1}, y_{2}, y_{3}, y_{4}, y_{5} y_{6} \quad(K=6)$ and 4 dependent variables as nodal voltages $V_{1}, V_{2}, V_{3}, V_{4} V_{5}(M=4)$ at the nodes $1,2,3,4$. Nonlinear elements have dependencies by the law: $y_{n 1}=a_{n 1}+b_{n 1} \cdot\left(V_{1}-V_{2}\right)^{2}, y_{n 2}=a_{n 2}+b_{n 2} \cdot\left(V_{2}-V_{3}\right)^{2}$. Nonlinearity parameters $b_{n 1}, b_{n 2}$ are equal to 1.0. The equation system of the optimization procedure and the system of the model have five and four equations respectively.

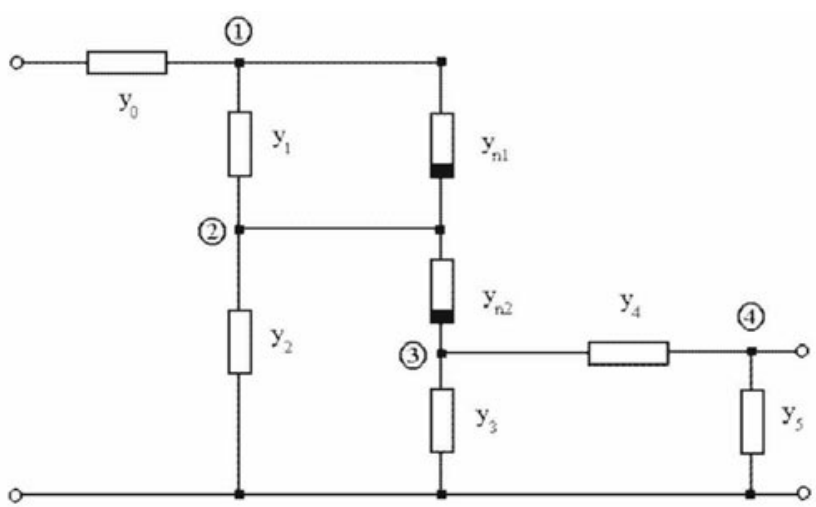

Figure 2. Circuit topology for $K=5, M=4$ 
The results of the analysis of the complete set of the design strategies with the fixed value of the control functions are given in Table III.

Table III. Complete set of design strategies for Example $2(M=4)$.

\begin{tabular}{|c|c|c|c|c|c|}
\hline \multirow[t]{2}{*}{$\mathrm{N}$} & \multirow{2}{*}{\begin{tabular}{|l|} 
Control functions \\
vector \\
$\mathrm{U}(\mathrm{u} 1, \mathrm{u} 2, \mathrm{u} 3, \mathrm{u} 4)$ \\
\end{tabular}} & Gradient & method & DFP & method \\
\hline & & \begin{tabular}{|l} 
Iterations \\
number
\end{tabular} & $\begin{array}{l}\text { Total design } \\
\text { time (sec) }\end{array}$ & \begin{tabular}{|l} 
Iterations \\
number
\end{tabular} & \begin{tabular}{|l} 
Total design \\
time (sec)
\end{tabular} \\
\hline 1 & $\left(\begin{array}{llll}0 & 0 & 0 & 0\end{array}\right)$ & 1077 & 0.522 & 207 & 0.251 \\
\hline \multirow{2}{*}{3} & $(0001)$ & 4893 & 0.379 & 533 & 0.081 \\
\hline & $(00010)$ & 1351 & 0.464 & 451 & 0.104 \\
\hline & $(0011)$ & 180 & 0.023 & 143 & 0.044 \\
\hline & $(010100)$ & 6715 & 2.301 & 156 & 0.091 \\
\hline & $(0101)$ & 4926 & 0.614 & 142 & 0.038 \\
\hline & $\left(\begin{array}{llll}0 & 1 & 1 & 0\end{array}\right)$ & 347 & 0.041 & 238 & 0.056 \\
\hline \multirow{2}{*}{8} & $(0111)$ & 7285 & 0.541 & 341 & 0.063 \\
\hline & $(1000)$ & 2196 & 0.787 & 72 & 0.043 \\
\hline \multirow{2}{*}{$\begin{array}{l}10 \\
11 \\
\end{array}$} & $(1001)$ & 4547 & 0.582 & 127 & 0.039 \\
\hline & $(1010)$ & 2169 & 0.283 & 162 & 0.042 \\
\hline \multirow{2}{*}{$\begin{array}{l}12 \\
13\end{array}$} & $(1011)$ & 5077 & 0.443 & 316 & 0.056 \\
\hline & $(1100)$ & 11904 & 1.478 & 388 & 0.134 \\
\hline \multirow{2}{*}{$\begin{array}{l}14 \\
15\end{array}$} & $(1101)$ & 26563 & 2.085 & 533 & 0.141 \\
\hline & $(1110)$ & 481 & 0.026 & 429 & 0.049 \\
\hline 16 & $(1111)$ & 18556 & 0.683 & 382 & 0.061 \\
\hline
\end{tabular}

There are 32 different strategies in this case. The strategy 3 is the optimal for the gradient method (4.07 sec) and the strategy 31 is the optimal for the DFP method $(0.17 \mathrm{sec})$, but as for the previous examples these strategies are not optimal in general either. The optimal trajectories were found by the special optimization procedure. The data of the optimal strategies are given in Table IV. The control function vector of each optimal strategy has one switching point. There is a time gain 63.2 and 55.2 for two optimization methods respectively.

Table IV. Data of the optimal design strategies for Example $2(M=4)$.

\begin{tabular}{|r|l|l|l|l|l|l|}
\hline $\mathrm{N}$ & Method & $\begin{array}{l}\text { Optimal control } \\
\text { functions vector } \\
\mathrm{U}(\mathrm{u} 1, \mathrm{u} 2, \mathrm{u3}, \mathrm{u4})\end{array}$ & $\begin{array}{l}\text { Iterations } \\
\text { number }\end{array}$ & $\begin{array}{l}\text { Switching } \\
\text { points }\end{array}$ & $\begin{array}{l}\text { Total } \\
\text { design } \\
\text { time }(\mathrm{sec})\end{array}$ & $\begin{array}{l}\text { Computer } \\
\text { time gain }\end{array}$ \\
\hline 1 & Gradient method & $(0011) ;(1111)$ & 350 & 50 & 0.025 & 20.8 \\
\hline 2 & DFP method & $(1111) ;(0000) ;(1111)$ & 138 & $30 ; 31$ & 0.014 & 17.9 \\
\hline
\end{tabular}

The results of all analyzed examples are the proof of the fact that the traditional design strategy is not the optimal one. The comparison of these examples gives an important conclusion: the time gain that can be obtained by the methodology described above increases when the system complexity grows. The computer time gain of the optimum design strategy with respect to the traditional design strategy as the function of the dependent parameters number $M$ is presented in Fig. 3. It is clear that this time gain increases very fast when the parameter $M$ increases.

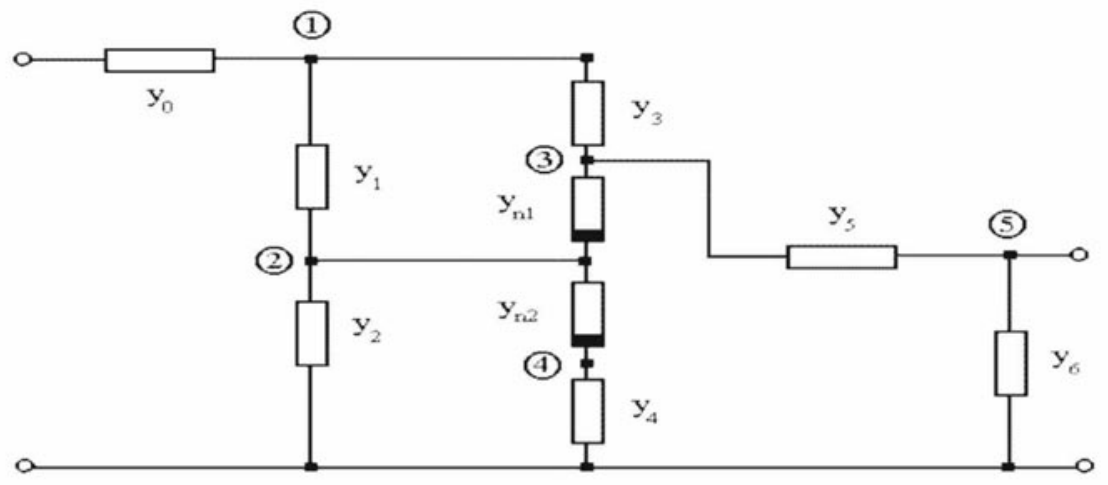

Figure 3. Circuit topology for $K=6, M=5$. 
Example 3. In Fig. 3 there is a circuit that has 6 independent variables as admittance $y_{1}, y_{2}, y_{3}, y_{4}, y_{5}, y_{6}(K=6)$ and 5 dependent variables as nodal voltages $V_{1}, V_{2}, V_{3}, V_{4}, V_{5} \quad(M=5)$ at the nodes $1,2,3,4$, 5 . Nonlinear elements have dependencies: $y_{n 1}=a_{n 1}+b_{n 1} \cdot\left(V_{3}-V_{2}\right)^{2}, y_{n 2}=a_{n 2}+b_{n 2} \cdot\left(V_{4}-V_{2}\right)^{2}$. Nonlinearity parameters $b_{n 1}, b_{n 2}$ in this case are equal to 1.0. The system of the optimization procedure equations and the system of the model's equations have six and five equations respectively.

Table V. Complete set of design strategies for Example $3(M=5)$.

\begin{tabular}{|c|c|c|c|c|c|}
\hline $\mathrm{N}$ & Control functions & Gradient & method & DFP & method \\
\hline & \begin{tabular}{|l} 
vector \\
$\mathrm{u}(\mathrm{u1}, \mathrm{u} 2, \mathrm{u} 3, \mathrm{u4}, \mathrm{u} 5)$ \\
\end{tabular} & \begin{tabular}{|l} 
Iterations \\
number
\end{tabular} & $\begin{array}{l}\text { Total design } \\
\text { time (sec) }\end{array}$ & \begin{tabular}{|l|} 
Iterations \\
number
\end{tabular} & \begin{tabular}{|l|} 
Total design \\
time (sec) \\
\end{tabular} \\
\hline 1 & $(00000)$ & 4580 & 6.32 & 911 & 1.27 \\
\hline 2 & $(00001)$ & 37750 & 37.29 & 2337 & 4.06 \\
\hline 3 & $(00010)$ & 3326 & $\begin{array}{l}4.07 \\
\end{array}$ & 966 & 1.98 \\
\hline 4 & $(00011)$ & 36803 & 31.86 & 416 & 0.65 \\
\hline 5 & $(00100)$ & 26954 & 34.11 & 2176 & 4.89 \\
\hline 6 & $(00101)$ & 243975 & 216.29 & 11197 & 18.62 \\
\hline 7 & $(00110)$ & 27146 & 23.24 & 626 & 0.88 \\
\hline 8 & $(00111)$ & 250042 & 146.54 & 9590 & 10.76 \\
\hline 9 & $(01000)$ & 18276 & 27.68 & 1808 & 4.95 \\
\hline 10 & $(01001)$ & 248026 & 213.61 & 11772 & 18.67 \\
\hline 11 & $(01010)$ & 15976 & 13.51 & 357 & 0.49 \\
\hline 12 & $(01011)$ & 263075 & 150.66 & 8054 & 8.73 \\
\hline 13 & $(01100)$ & 29825 & 31.81 & 1392 & 2.52 \\
\hline 14 & $(01101)$ & 329023 & 194.54 & 11532 & 12.86 \\
\hline 15 & $(01110)$ & 34117 & 7.97 & 475 & 0.19 \\
\hline 16 & $(01111)$ & 272594 & 50.37 & 5784 & 2.41 \\
\hline 17 & $(10000)$ & 4846 & 4.89 & 1728 & 2.97 \\
\hline 18 & $(10001)$ & 30257 & 21.86 & 3449 & 4.39 \\
\hline 19 & $(10010)$ & 7320 & 6.53 & 179 & 0.25 \\
\hline 20 & $(10011)$ & 111981 & 69.65 & 3074 & 3.29 \\
\hline 21 & $(10100)$ & 24240 & 22.18 & 1627 & 2.47 \\
\hline 22 & $(10101)$ & 245411 & 152.21 & 11148 & 12.03 \\
\hline 23 & $(10110)$ & 21612 & 13.19 & 372 & 0.33 \\
\hline 24 & $(10111)$ & 234092 & 97.32 & 6438 & 4.73 \\
\hline 25 & $(11000)$ & 26646 & 28.02 & 1343 & 2.47 \\
\hline 26 & $(11001)$ & 293634 & 170.76 & 11204 & 12.08 \\
\hline 27 & $(11010)$ & 31585 & 18.18 & 395 & 0.36 \\
\hline 28 & $(11011)$ & 266903 & 103.75 & 5470 & 4.12 \\
\hline 29 & $(11100)$ & 26711 & 19.12 & 962 & 1.11 \\
\hline 30 & $(11101)$ & 350735 & 138.63 & 9437 & 7.25 \\
\hline 31 & $(11110)$ & 41541 & 7.74 & 505 & 0.17 \\
\hline 32 & $(11111)$ & 113885 & 7.86 & 1267 & 0.22 \\
\hline
\end{tabular}

The results of the analysis of the complete set of the design strategies with the fixed value of the control functions are given in Table $\mathrm{V}$.

There are 32 different strategies in this case. The strategy 3 is the optimal for the gradient method $(4.07 \mathrm{sec}$ ) and the strategy 31 is the optimal for the DFP method $(0.17 \mathrm{sec})$, but as for the previous examples these strategies are not optimal in general either. The optimal trajectories were found by the special optimization procedure. The data of the optimal strategies are given in Table VI. The control function vector of each optimal strategy has one switching point. There is a time gain 63.2 and 55.2 for two optimization methods respectively.

Table VI. Data of the optimal design strategies for Example 3 (M=5).

\begin{tabular}{|r|l|l|l|l|l|l|}
\hline $\mathrm{N}$ & Method & $\begin{array}{l}\text { Optimal control } \\
\text { functions vector } \\
\mathrm{U}(\mathrm{u} 1, \mathrm{u} 2, \mathrm{u3}, \mathrm{u4}, \mathrm{u} 5)\end{array}$ & $\begin{array}{l}\text { Iterations } \\
\text { number }\end{array}$ & $\begin{array}{l}\text { Switching } \\
\text { points }\end{array}$ & $\begin{array}{l}\text { Total } \\
\text { design } \\
\text { time (sec) }\end{array}$ & $\begin{array}{l}\text { Computer } \\
\text { time gain }\end{array}$ \\
\hline 1 & Gradient method & $(00011) ;(11111)$ & 824 & 55 & 0.101 & 63.2 \\
\hline 2 & DFP method & $(10010) ;(11111)$ & 37 & 18 & 0.023 & 55.2 \\
\hline
\end{tabular}


The results of all analyzed examples are the proof of the fact that the traditional design strategy is not the optimal one. The comparison of these examples gives an important conclusion: the time gain that can be obtained by the methodology described above increases when the system complexity grows. The computer time gain of the optimum design strategy with respect to the traditional design strategy as the function of the dependent parameters number $M$ is presented in Fig. 4. It is clear that this time gain increases very fast when the parameter $M$ increases.

\subsection{Active Nonlinear Circuits}

In Fig. 4 there is a circuit of the amplifier that consists of three transistor cells. The one-cell transistor circuit was analyzed as the first example. In this case the circuit includes three nodes only. The second circuit includes two transistor cells and the five-node circuit was analyzed in this case. The last situation includes the full circuit of Fig. 4 with three transistors and seven nodes. The design process has been realized on DC mode for all the circuits above mentioned. The Ebers-Moll static model of the transistor has been used. The objective function $C(X)$ has been determined as the sum of the squared differences between beforehand-defined values and current values of the voltages for the transistor junctions.

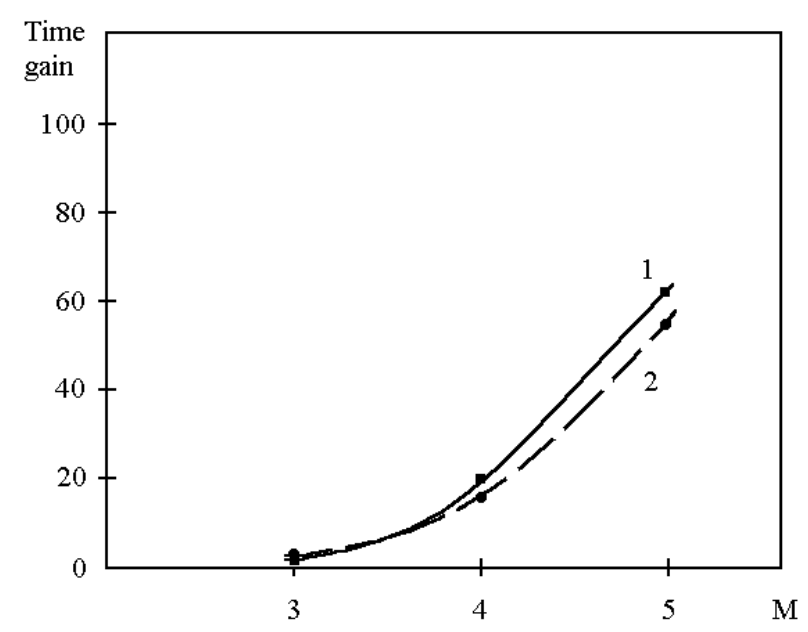

Figure 4. Computer time gain of the optimal design strategy for the passive nonlinear circuits. 1-Gradient method, 2-DFP method.

Example 3. The one cell circuit has three independent variables as admittance $y_{1}, y_{2}, y_{3}(K=3)$ and three dependent variables as nodal voltages $V_{1}, V_{2}, V_{3}(M=3)$. The results of the analysis of the complete set of the design strategies with the fixed value of the control functions are given in Table 5. The optimal strategy has two switching points and has time gain 80 and 94 for two optimization methods respectively (Table VI).

Example 4. The full circuit of Fig. 4 has seven independent variables as admittance $y_{1}, y_{2}, y_{3}, y_{4}, y_{5}, y_{6}, y_{7}(K=\lambda)$ and seven dependent variables as nodal voltages $V_{1}, V_{2}, V_{3}, V_{4}, V_{5}, V_{6}, V_{7}(M=\lambda$. The results of the analysis of the traditional design strategy, modified traditional strategy and some intermediate strategies with the fixed value of the control functions are given in Table VII. All the strategies have the design time lesser than the traditional strategy. The data of the optimal strategies are given in Table VIII. The optimal strategy has the computer time gain 2390 for the gradient method and 1614 for the DFP method. The potential computer time gain of the optimum design strategy with respect to the traditional design strategy as the function of the transistor number $N_{\text {re }}$ is presented in Fig. 5. The time gain increases very fast for the nonlinear active transistor circuits. 
Table VII. Complete set of design strategies for one transistor cell amplifier ( $M=3$ ).

\begin{tabular}{|c|c|c|c|c|c|}
\hline \multirow[t]{2}{*}{$\mathrm{N}$} & \multirow{2}{*}{$\begin{array}{l}\text { Control functions } \\
\text { vector } \\
\mathrm{U}(\mathrm{U1}, \mathrm{U} 2, \mathrm{U} 3)\end{array}$} & Gradient & \multirow{2}{*}{$\begin{array}{l}\text { method } \\
\begin{array}{l}\text { Total design } \\
\text { time (sec) }\end{array} \\
\end{array}$} & \multirow{2}{*}{\begin{tabular}{|l} 
DFP \\
Iterations \\
number
\end{tabular}} & \multirow{2}{*}{$\begin{array}{l}\text { method } \\
\begin{array}{l}\text { Total design } \\
\text { time (sec) }\end{array} \\
\end{array}$} \\
\hline & & $\begin{array}{l}\text { Iterations } \\
\text { number }\end{array}$ & & & \\
\hline 1 & $(000)$ & 50707 & 13.84 & 11097 & 5.54 \\
\hline 2 & $(001)$ & 43822 & 9.06 & 1413 & 0.55 \\
\hline 3 & $(010)$ & 184136 & 38.34 & 55748 & 21.48 \\
\hline 4 & $(011)$ & 45315 & 9.67 & 7198 & 2.69 \\
\hline 5 & $(100)$ & 88811 & 18.29 & 14820 & 5.71 \\
\hline 6 & (101) & 2270 & 0.43 & 375 & 0.12 \\
\hline 7 & $(110)$ & 22435 & 4.34 & 11977 & 4.45 \\
\hline 8 & $(111)$ & 9459 & 0.59 & 1461 & 0.23 \\
\hline
\end{tabular}

Table VIII. Data of the optimal design strategies for one transistor cell amplifier ( $M=3)$.

\begin{tabular}{|r|l|l|l|l|l|l|}
\hline $\mathrm{N}$ & Method & $\begin{array}{l}\text { Optimal control } \\
\text { functions vector } \\
\mathrm{U}(\mathrm{u} 1, \mathrm{u} 2, \mathrm{u3})\end{array}$ & $\begin{array}{l}\text { Iterations } \\
\text { number }\end{array}$ & $\begin{array}{l}\text { Switching } \\
\text { points }\end{array}$ & $\begin{array}{l}\text { Total } \\
\text { design } \\
\text { time (sec) }\end{array}$ & $\begin{array}{l}\text { Computer } \\
\text { time gain }\end{array}$ \\
\hline 1 & Gradient method & $(101) ;(111)$ & 2779 & 2 & 0.173 & 80 \\
\hline 2 & DFP method & $(101) ;(111)$ & 377 & 2 & 0.059 & 94 \\
\hline
\end{tabular}

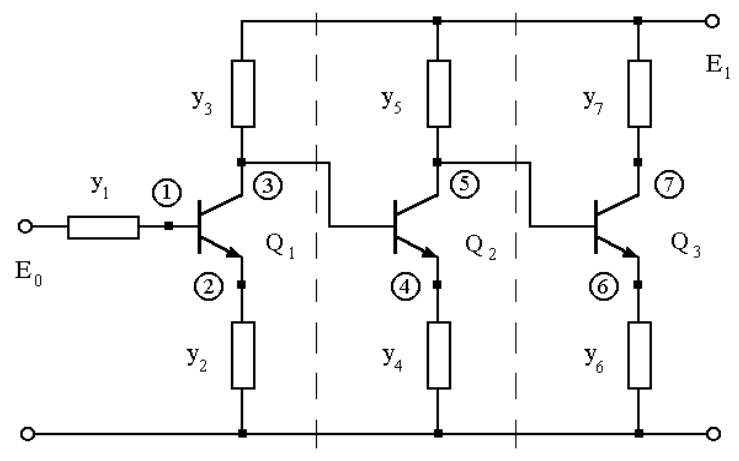

Figure 5. Circuit topology for three-transistor cell amplifier.

All obtained results confirm the rule that the total computer time gain of the time-optimal design strategy increases when the complexity of the circuit increases. The comparison of the results for passive and active circuits shows that the computer time gain is larger for the active circuits because of larger complexity in this last case.

\section{ADDITIONAL ACCELERATION EFFECT}

On the basis of the described methodology an additional acceleration effect of the design process was discovered. This effect appears for all analyzed circuits. We start with the simplest electronic circuit that has two parameters only $(N=2)$ and has no any practical sense, but services well to understand the processes that occur in the design procedure. Then we analyze the $N$-dimensional problem, where $N$ has variation from 6 to 14 . All these examples demonstrate the additional acceleration effect that appears due to the different design trajectory behavior with the different control functions defined by the new design methodology. 


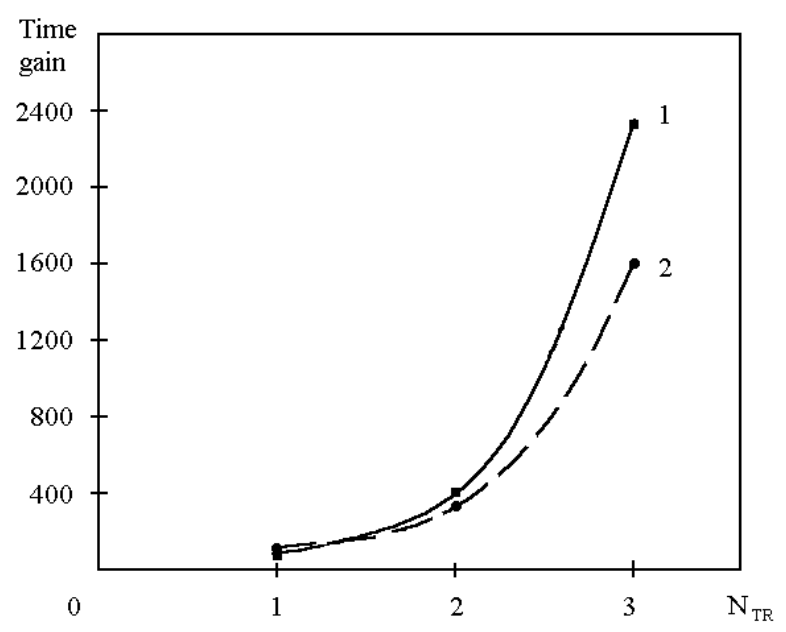

Figure 6. Computer time gain of the optimal design strategy for the active nonlinear circuits. 1-Gradient method, 2-DFP method.

6.1 Two-dimensional problem

There is an analysis of a simplest electronic circuit with the topology, which is shown in Fig. 6. We suppose that the element $r_{1}$ has a nonlinear dependency in general case: $r=r_{10}+b_{n} \cdot V_{1}^{2}$. There are only two variable parameters in this circuit, the resistance $r_{2}$ and the voltage $V_{1}$. The element $r_{2}$ is supposed as an independent parameter (K=1) and the voltage $V_{1}$ as a dependent parameter $(M=1)$. Vector $X$ of the state variables has two components $X=\left(x_{1}, x_{2}\right)$ where $x_{1}^{2} \equiv r_{2}, x_{2} \equiv V_{1}$. The model of the system is given by: $x_{2}=\frac{x_{1}^{2}}{x_{1}^{2}+r_{10}+b_{n} x_{2}^{2}}$. This equation is transformed to the normal form as:

$$
g_{1}(X) \equiv\left(x_{1}^{2}+r_{10}+b_{n} x_{2}^{2}\right) x_{2}-x_{1}^{2}=0
$$

The objective function is defined by the formula $C(X)=\left(x_{2}-k_{V}\right)^{2}$, where $k_{V}$ has a fixed value. There is only one control function $u_{1}$ in this case because there is only one dependent parameter $x_{2}$. The design trajectory for this example is the curve in two-dimensional space, if the numerical design algorithm is applied. At the same time, the numerical analysis of this simple circuit has no sense, because there is an analytic solution for this problem. We can obtain this solution by means of the Lagrange multipliers for instance. However, we provide the numerical analysis of this circuit to reveal the essential features of the new additional design process acceleration effect. The main features of this analysis appear in all other examples too.

The trajectories, which correspond to the gradient optimization method and the initial vector $X_{\text {in }}$ with the components $(1,1)$ are presented in Fig. 7 (a), (b), (c) for two strategies and for three different values of the nonlinearity parameter $b_{n}\left(10^{-5}, 1.0,5.0\right)$. Solid lines in this figure correspond to the traditional design strategy $\left(u_{1}=0\right)$; dash lines correspond to the modified traditional strategy $\left(u_{1}=1\right)$. The optimal trajectories coincide with trajectories of the traditional design strategy. 


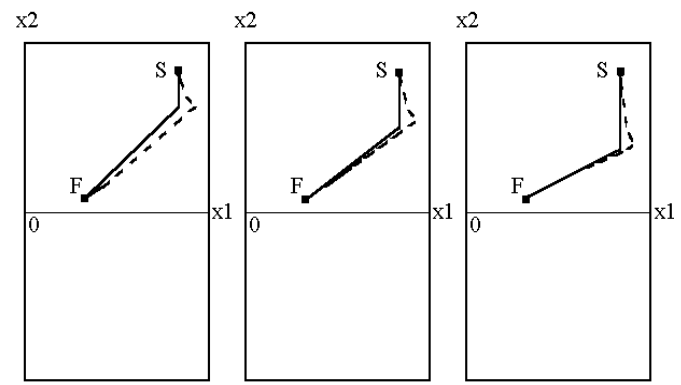

(a)

(b)

(c)

Figure 7. Trajectories for the traditional strategy (solid line) and for the modified traditional strategy (dash line) for $X_{\text {in }}=(1,1)$ : a) $b_{n}=10^{-5}$; b) $b_{n}=1.0$; c) $b_{n}=5.0$.

Another trajectory behavior is observed when the initial value of the parameter $x_{2}$ is negative. The trajectories for three different values of the parameter $b_{n}$ are presented in Fig. 8 (a), (b), (c), for $X_{\text {in }}=(1,-1)$.

The trajectories that correspond to the traditional design strategy practically do not have dependency from the initial value of the component $x_{2}$. There is only one jump in the start point $S$ to the principal part of the trajectory line from above (when $x_{2}=1$, Fig.7) or from below (when $x_{2}=-1$, Fig.8). Another situation is observed when the modified traditional strategy is used for $x_{2}=-1$. The first part of the trajectory lies in a physically unreal sub-space $\left(x_{2}<0\right)$ and the second part lies in a real sub-space $\left(x_{2}>0\right)$. Moreover, it is very important to note that the movement along the trajectory is very fast from the start point $S$ to the point $R$. On the other hand the movement is by far slower from the point $R$ to the finish point $F$. It is very important that the trajectories, which correspond to the traditional and to the modified traditional strategies draw to the finish point $F$ from the opposite directions. The unique possibility to accelerate the design process is created when the switching point of the control function $u_{1}$ lies in the point, which is the projection of the finish point $F$ to the modified traditional strategy trajectory, which lies in unreal subspace. This is the point $S w$. The optimal trajectory has two parts in this case. The first part corresponds to the curve $S$ - $S w$. During the movement along this curve the control function $u_{1}$ is equal to 1 . The control function $u_{1}$ at the time moment, which corresponds to the point Sw changes the value to 0 . At this moment the jump is realized from the point $S w$ to the finish point $F$ or very near to the point $F$ (it depends on the calculate step). Therefore a great acceleration of the design process takes place. This acceleration effect is observed for all values of the nonlinearity parameter $b_{n}$. The optimal trajectory has two parts in this case. The computer time gain of the optimal design strategies with respect to the traditional design strategy by the acceleration effect is equal to 4.91, 3.53 for the gradient method and DFP method respectively. This effect is observed for more complicate examples too. However, in this case a trajectory line of the design process lies in $N$-dimensional design space and we need to analyze different projections of $N$ dimensional curves.

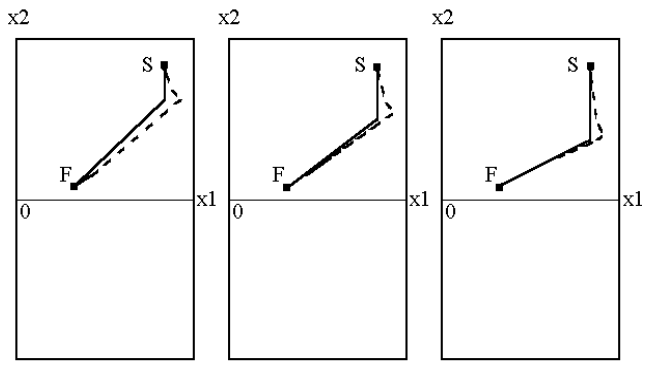

(a)

(b)

(c)

Figure 8. Trajectories for the traditional strategy (solid line) and for the modified traditional strategy (dash line) for $X_{\text {in }}=(1,1)$ : a) $b_{n}=10^{-5}$; b) $b_{n}=1.0 ;$ c) $b_{n}=5.0$. 


\section{$6.2 \mathrm{~N}$-dimensional problem}

In general case, we have $N$-dimensional design problem. However, all the specific features of the additional design acceleration, as a necessary trajectory jump, and a time gain are revealed again. All examples of the section 5 were analyzed with the negative value of some coordinates of the initial vector $X_{i n}$. The final results are concentrated in Tables IX-XII for four above mentioned examples. The dependencies of the potential computer time gain for the optimum design strategy with an additional acceleration as the function of the dependent parameters number $M$ for the nonlinear passive circuits and as the function of the transistor number $N_{\mathbb{R}}$ for the nonlinear active circuits are presented in Fig. 9 and Fig. 10 respectively. The data comparison in Fig. 3 and Fig. 9 for the passive nonlinear circuits with and without an additional acceleration effect shows that this effect is displayed for all analyzed examples and gives an additional time gain from 35\% to 350\% depending on the problem dimension and optimization method.

\section{Table IX. Data of the optimal design strategies for Example $1(M=3)$ with an additional acceleration effect.}

\begin{tabular}{|r|l|l|l|l|l|l|}
\hline N & Method & $\begin{array}{l}\text { Optimal control } \\
\text { functions vector } \\
\mathrm{U}(\mathrm{u} 1, \mathrm{u} 2, \mathrm{u3})\end{array}$ & $\begin{array}{l}\text { Iterations } \\
\text { number }\end{array}$ & $\begin{array}{l}\text { Switching } \\
\text { points }\end{array}$ & $\begin{array}{l}\text { Total } \\
\text { design } \\
\text { time (sec) }\end{array}$ & $\begin{array}{l}\text { Computer } \\
\text { time gain }\end{array}$ \\
\hline 1 & Gradient method & $(111) ;(000) ;(111)$ & 398 & $87 ; 88$ & 0.0101 & 17.6 \\
\hline 2 & DFP method & $(111) ;(000) ;(111)$ & 170 & $40 ; 41$ & 0.0065 & 13.2 \\
\hline
\end{tabular}

Table X. Data of the optimal design strategies for Example $2(M=5)$ with an additional acceleration effect.

\begin{tabular}{|r|l|l|l|l|l|l|}
\hline $\mathrm{N}$ & Method & $\begin{array}{l}\text { Optimal control } \\
\text { functions vector } \\
\mathrm{U}(\mathrm{u1}, \mathrm{u2}, \mathrm{u3}, \mathrm{u4}, \mathrm{u} 5)\end{array}$ & $\begin{array}{l}\text { Iterations } \\
\text { number }\end{array}$ & $\begin{array}{l}\text { Switching } \\
\text { points }\end{array}$ & $\begin{array}{l}\text { Total } \\
\text { design } \\
\text { time (sec) }\end{array}$ & $\begin{array}{l}\text { Computer } \\
\text { time gain }\end{array}$ \\
\hline 1 & Gradient method & $(11111) ;(00000) ;(11111)$ & 501 & $10 ; 40$ & 0.074 & 85.4 \\
\hline 2 & DFP method & $(11111) ;(10000) ;(11111)$ & 35 & $10 ; 16$ & 0.015 & 84.6 \\
\hline
\end{tabular}

Table XI. Data of the optimal design strategies for one-transistor cell amplifier with an additional acceleration effect.

\begin{tabular}{|r|l|l|l|l|l|l|}
\hline$N$ & Method & $\begin{array}{l}\text { Optimal control } \\
\text { functions vector } \\
\mathrm{U}(\mathrm{u} 1, \mathrm{u2}, \mathrm{u3})\end{array}$ & $\begin{array}{l}\text { Iterations } \\
\text { number }\end{array}$ & $\begin{array}{l}\text { Switching } \\
\text { points }\end{array}$ & $\begin{array}{l}\text { Total } \\
\text { design } \\
\text { time (sec) }\end{array}$ & $\begin{array}{l}\text { Computer } \\
\text { time gain }\end{array}$ \\
\hline 1 & Gradient method & $(111) ;(000) ;(111)$ & 1341 & $5 ; 6$ & 0.083 & 166 \\
\hline 2 & DFP method & $(111) ;(000) ;(111)$ & 230 & $2 ; 3$ & 0.036 & 154 \\
\hline
\end{tabular}

Table XII. Data of the optimal design strategies for three-transistor cell amplifier with an additional acceleration effect.

\begin{tabular}{|l|l|l|r|r|l|l|}
\hline$N$ & $\begin{array}{l}\text { Optimal control } \\
\text { functions vector } \\
\mathrm{U}(\mathrm{u} 1, \mathrm{u} 2, \mathrm{u3}, \mathrm{u} 4, \mathrm{u} 5, \mathrm{u} 6, \mathrm{u} 7)\end{array}$ & $\begin{array}{l}\text { Iterations } \\
\text { number }\end{array}$ & $\begin{array}{l}\text { Switching } \\
\text { points }\end{array}$ & $\begin{array}{l}\text { lotal } \\
\text { design } \\
\text { time }(\mathrm{sec})\end{array}$ & $\begin{array}{l}\text { Computer } \\
\text { time gain }\end{array}$ \\
\hline 1 & Gradient method & $(111111) ;(0000000) ;(1111111)$ & 5090 & $10 ; 11$ & 1.82 & 7721 \\
\hline 2 & DFP method & $(1111111) ;(0000000) ;(1111111)$ & 462 & $2 ; 3$ & 0.33 & 4306 \\
\hline
\end{tabular}




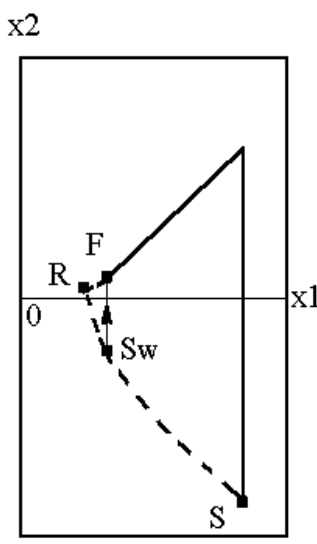

(a)

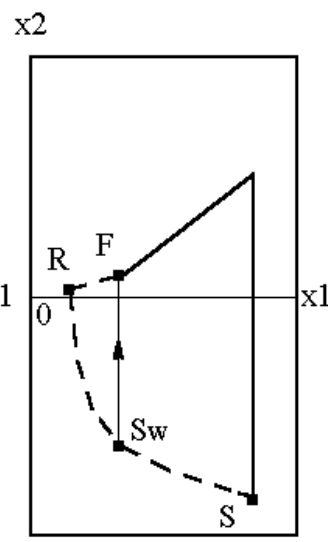

(b)

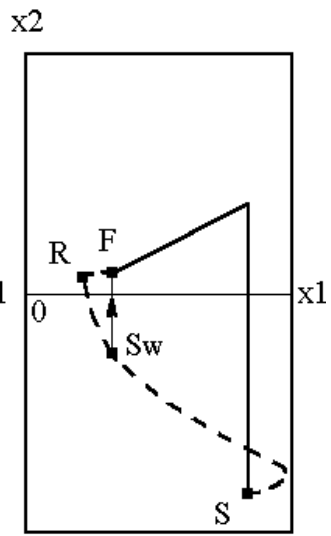

(c)

Figure 9. Trajectories for the traditional strategy (solid line) and for the modified traditional strategy (dash line) for $X_{\text {in }}=(1,-1)$ : a) $b_{n}=10^{-5}$; b) $b_{n}=1.0$; c) $b_{n}=5.0$.

The additional acceleration effect is observed for the active circuits too; however in this case the analysis is more complicated because the trajectory design line not always exists due to the specific current dependency of the transistor junctions. The trajectory behavior near the end point has a great influence to the acceleration effect quantitative value. The complex behavior of the trajectories can complicate the acceleration effect achievement because there is more than one jump required in this case. The data comparison in Fig. 5 and Fig. 10 shows a large additional acceleration. The total computer time gain of the optimal strategy for the last example (three transistor cells circuit with 7 nodes and 14 variables) due to the acceleration effect is equal to 7721 for the gradient optimization method and 4306 for the DFP method. This value of the computer time gain shows a great perspective of further research in this direction. Now it is clear that the start point of the optimal design process must be elected with at least one negative coordinate and the first part of the optimal design trajectory lies in unreal state space. The other part of the optimal design strategy consists of one or several jumps with the special adjusted trajectories of the different admissible strategies.

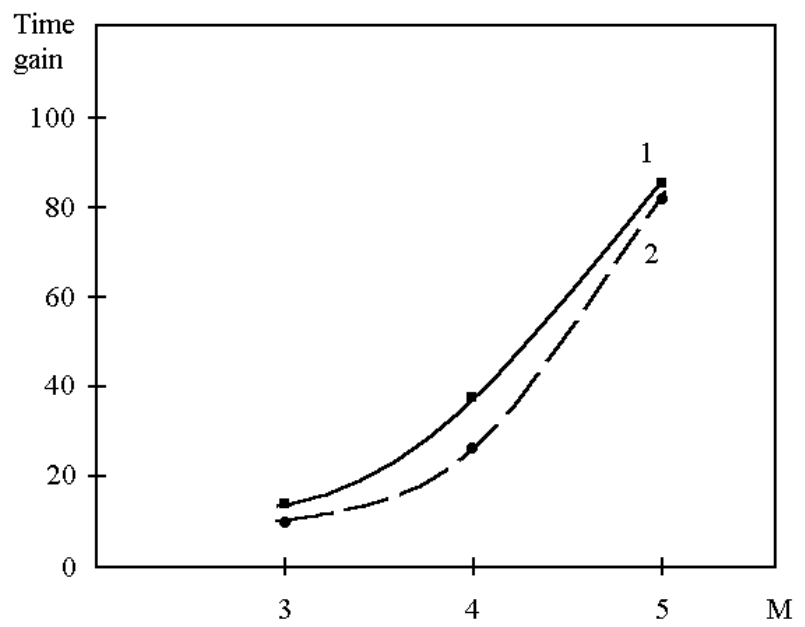

Figure 10. Computer time gain of the optimal design strategy with an additional acceleration effect for the passive nonlinear circuits. 1-Gradient method, 2-DFP method. 
The additional acceleration effect, which is discussed here, serves as an excellent example of a new qualitative result, which was obtained by the generalized system design methodology. It is clear that all these advantages of the new approach are realized when the time-optimal algorithm is constructed. One of the main problems on this way is the definition of the specific characteristics and special features of the optimal or quasi-optimal design algorithm. The results obtained here serve as the first step for the optimal design algorithm characteristic determined, particularly for the initial point optimal selection and for the preliminary definition of the optimal trajectory and control function structure.

\section{IMPLEMENTATION ASPECT}

All numerical results have been obtained on the basis of computer Pentium I, $100 \mathrm{MHz}, 64 \mathrm{MB}$ RAM with compiler Turbo $\mathrm{C}$ and double precision for all real numbers.

\section{CONCLUSIONS}

The traditional design algorithm is not a time-optimal. The problem of the optimum algorithm construction can be solved more adequately on the basis of the optimal system design theory. This theory can be formulated as the minimum-time problem of the control theory. In this case it is necessary to select one optimal trajectory from the infinite number of the different design strategies, which are produced. The maximum principle serves in this case as the basis for the determination of the optimal dependency of all control functions. In that case it is possible to reduce considerably the total computer time for the system design. The analysis of the different electronic systems gives the possibility to conclude that the computer time gain of the optimal strategy increases when the size and complexity of the system increase. The additional acceleration effect of the system design process was discovered by means of the variation of the initial value of the state variables and the special control functions. This effect exists due to the very different behavior of the design trajectories that have various control functions and different start points in the design space. This new effect reduces the total computer time additionally and gives the perspective to accelerate more the system design process. On the other hand, the obtained results give useful information about the initial point selection for the optimal design process and about the structure of the optimal or quasi-optimal design trajectory.

\section{ACKNOWLEDGMENTS}

This work was supported partially by the Universidad Autonoma de Puebla, under project VIEPIII05G02.

\section{REFERENCES}

[1] Bunch J.R. and Rose D.J., (Eds), Sparse Matrix Computations, New York: Academic Press, 1976.

[2] Duff I. S. and Reid J.K., "Some Design Features of a Sparse Matrix Code", ACM Trans. on Mathematical Software, Vol. 5, No. 1, pp. 18-35. 1979.

[3] Osterby O. and Zlatev Z., Direct Methods for Sparse Matrices, New York: Springer-Verlag, 1983.

[4] George A., "On Block Elimination for Sparse Linear Systems", SIAM J. Numer. Anal. Vol. 11, No.3, pp. 585-603. 1984.

[5] Wu F.F., "Solution of Large-Scale Networks by Tearing", IEEE Trans. Circuits Syst., Vol. CAS-23, No. 12, pp. 706-713. 1976.

[6] Sangiovanni-Vincentelli A., Chen L.K. and Chua L.O., "An Efficient Cluster Algorithm for Tearing Large-Scale Networks", IEEE Trans. Circuits Syst., Vol. CAS-24, No. 12, pp. 709-717. 1977.

[7] Rabat N., Ruehli A.E., Mahoney G.W. and Coleman J.J., "A Survey of Macromodeling", Proceedings of the IEEE Int. Symp. Circuits Systems, April, pp. 139-143. 1985.

[8] Ruehli A.E., Sangiovanni-Vincentelli A. and Rabbat G., "Time Analysis of Large-Scale Circuits Containing One-Way Macromodels", IEEE Trans. Circuits Syst., Vol. CAS-29, No. 3, pp. 185-191. 1982.

[9] Gill P.E., Murray W. and Wright M.H., Practical optimization, London: Academic Press, 1981.

[10] Fletcher R., Practical Methods of Optimization, New York: John Wiley and Sons, Vol. 1, 1980, Vol. 2, 1981. 
[11] Brayton R.K., Hachtel G.D. and Sangiovanni-Vincentelli A.L., "A survey of optimization techniques for integratedcircuit design", Proceedings IEEE, Vol. 69, pp. 1334-1362. 1981.

[12] Ruehli A.E., (Ed.), Circuit Analysis, Simulation and Design, Vol. 3, part 2, Amsterdam: Elsevier Science Publishers, 1987.

[13] Massara R.E., Optimization Methods in Electronic Circuit Design, Harlow: Longman Scientific \& Technical, 1991.

[14] Zemliak A., "System Design Problem Formulation by Control Theory", Proceedings of the IEEE Int. Symp. Circuits Systems, Sydney, Australia, May, Vol. 5, pp. 5-8. 2001.

[15] Zemliak A., "General Methodology for System Design”, in Modern Applied Mathematics Techniques in Circuits, Systems and Control, N. Mastorakis (ed), Athens: Word Scientific and Engineering Society Press, pp. 150-155. 1999.

[16] Zemliak A., "Analog System Design Problem Formulation by Optimum Control Theory", IEICE Trans. on Fundamentals of Electronics, Comunications and Computer Sciencies, Vol. E84-A, No. 8, pp. 2029-2041. 2001.

[17] Fletcher R and Powell M.J.D., "A Rapidly Convergent Descent Method for Minimization", Comput. J., No. 6, pp. 163-168. 1963.

[18] Kashirskiy I.S. and Trokhimenko Ya.K., General Optimization for Electronic Circuits, Kiev: Tekhnika, 1979.

[19] Pontryagin L.S., Boltyanskii V.G., Gamkrelidze R.V. and Mishchenko E.F., The Mathematical Theory of Optimal Processes, New York: Interscience Publishers, Inc., 1962.

[20] Neustadt L.W., "Synthesis of Time-Optimal Control Systems", J. of Math. Analysis and Applications, No. 1, pp. 484-492. 1960.

[21] Krylov I.A., and Chernousko F.L., "Consecutive Approximation Algorithm for Optimal Control Problems", J. of Numer. Math. and Math. Pfysics, Vol. 12, No 1, pp. 14-34. 1972.

[22] Krotov V.F., Global Methods in Optimal Control Theory, New York: Marcel Dekker, Inc., 1996.

[23] Sepulchre R., Jankovic M., and Kokotovic P.V., Constructive Nonlinear Control, New York: Springer-Verlag, 1997.

[24] Pytlak R., Numerical Methods for Optimal Control Problems with State Constraints, Berlin: Springer-Verlag, 1999.

Authors Byography

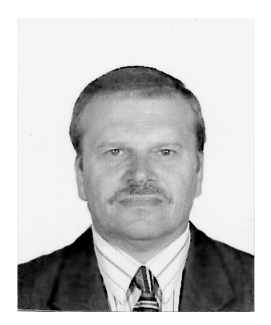

Alexander Zemliak

Was born in Russia in 1948. He received the M.Sc. and Ph.D. degrees from the Kiev Polytechnic Institute (KPI), Kiev, Ukraine, in 1972 and 1976, respectively, both in Electronic Engineering. From 1972 to 1976, he was a Researcher at the Department of Radioelectronic Systems, KPI. From 1976 to 1994, he worked as a Professor at KPI. From 1994 he is a Professor of the Physics and Mathematics Department at the Universidad Autónoma de Puebla, Mexico. His research interest is in computer-aided RF and microwave system analysis and design, optimal design methodology, computational electromagnetics, numerical techniques in the simulation, analysis and optimization of microwave devices. He has authored over 150 papers in refereed journals and conference proceedings. 


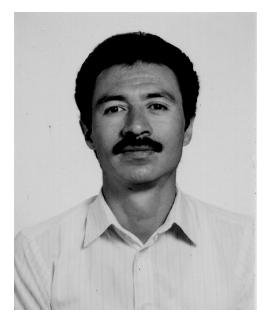

Eduardo Ríos Silva

Was born in Mexico in 1956. He received the B Sc. degree in Electronics and Communications from the Instituto Politécnico Nacional, Mexico, in 1982, and the M.Sc. degree in Mechanical Engineering from the Instituto Tecnológico de Puebla, Mexico in 1996. From 1985 to 2003 he worked as Associated Professor in the Electronic Department at the Universidad Autónoma de Puebla, Mexico. He is currently completing a Ph.D. thesis. His research interest includes analysis and optimal design of RF circuits.

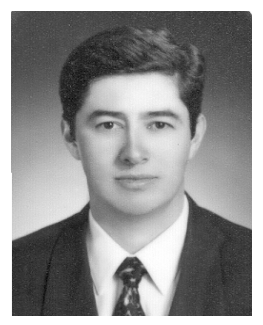

\section{Pedro Amado Miranda Romagnoli}

Was born in Mexico in 1963. He received the B.Sc. degree in Electronics, the M.Sc. and Ph.D. degrees in Optoelectronics, all of them from the Universidad Autónoma de Puebla (BUAP), Puebla, Mexico, in 1992, 1997 and 2002, respectively. From 1992 to 1999 he worked as Associated Professor in the Physics and Mathematics Department at BUAP. He is currently a Professor at the Centro de Investigación Avanzada en Ingeniería Industrial (CIAII), Universidad Autónoma del Estado de Hidalgo (UAEH), Pachuca, Mexico. His research interest includes optimization, modeling, optimal design and RF circuits design.

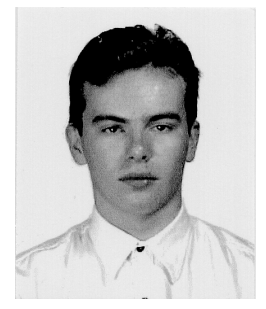

Kirill Zemliak

Was born in Ukraine in 1981. He is an undergraduate student of the Computer Science Department at the Universidad Autónoma de Puebla, Mexico. His current studies include the modeling and simulation of electronic systems. 